\title{
Amorphous Vanadium Titanates as a Negative Electrode for Lithium-ion Batteries
}

\author{
Jeong Beom Lee ${ }^{1}$, Oh. B. Chae ${ }^{2}$, Seulki Chae ${ }^{1}$, Ji Heon Ryu ${ }^{3}$, and Seung M. Oh ${ }^{1 *}$ \\ ${ }^{1}$ Department of Chemical and Biological Engineering and Institute of Chemical Processes, Seoul National University, 1 \\ Gwanak-ro, Gwanak-gu, Seoul 08826, Republic of Korea \\ ${ }^{2}$ Battery R\&D, LG Chem. Research Park, LG Chem. Ltd., 188 Munji-ro, Yuseong-gu, Daejeon 34122, Republic of Korea \\ ${ }^{3}$ Graduate School of Knowledge-based Technology and Energy, Korea Polytechnic University, 237 Sangidaehak-ro, \\ Siheung-si, Gyeonggi 15073, Republic of Korea
}

\begin{abstract}
Amorphous vanadium titanates ( $a$ VTOs) are examined for use as a negative electrode in lithium-ion batteries. These amorphous mixed oxides are synthesized in nanosized particles $(<100 \mathrm{~nm})$ and flocculated to form secondary particles. The $\mathrm{V}^{5+}$ ions in $a \mathrm{VTO}$ are found to occupy tetrahedral sites, whereas the $\mathrm{Ti}^{4+}$ ions show fivefold coordination. Both are uniformly dispersed at the atomic scale in the amorphous oxide matrix, which has abundant structural defects. The first reversible capacity of an $a$ VTO electrode $\left(295 \mathrm{~mA} \mathrm{~h} \mathrm{~g}^{-1}\right)$ is larger than that observed for a physically mixed electrode $\left(1: 2 a \mathrm{~V}_{2} \mathrm{O}_{5} \mid\right.$ $\left.a \mathrm{TiO}_{2}, 245 \mathrm{~mA} \mathrm{~h} \mathrm{~g}^{-1}\right)$. The discrepancy seems to be due to the unique four-coordinated $\mathrm{V}^{5+}$ ions in $a \mathrm{VTO}$, which either are more electron-accepting or generate more structural defects that serve as $\mathrm{Li}^{+}$storage sites. Coin-type $\mathrm{Li} / a \mathrm{VTO}$ cells show a large irreversible capacity in the first cycle. When they are prepared under nitrogen $(a \mathrm{VTO}-\mathrm{N})$, the population of surface hydroxyl groups is greatly reduced. These groups irreversibly produce highly resistive inorganic compounds ( $\mathrm{LiOH}$ and $\mathrm{Li}_{2} \mathrm{O}$ ), leading to increased irreversible capacity and electrode resistance. As a result, the material prepared under nitrogen shows higher Coulombic efficiency and rate capability.
\end{abstract}

Keywords : Amorphous metal oxides, Lithium-ion batteries, X-ray absorption fine structure (XAFS), Surface hydroxyl groups, Electrochemistry

Received : 24 November 2016, Accepted : 12 December 2016

\section{Introduction}

Since lithium-ion batteries (LIBs) were first commercialized in 1991, the market for their use in portable electronic devices and electric vehicles (EVs) has grown steadily $[1,2]$. The market could be further expanded if the cell performance is improved in terms of capacity, power, safety, and cycle life [3]. Unfortunately, current LIBs cannot fully satisfy the high-power demand of EVs. One reason for this limitation is the use of graphite negative electrodes; the working potential of graphite is so close to that of $\mathrm{Li}$ metal that Li plating is highly probable under high-

*E-mail address: seungoh@snu.ac.kr DOI: https://doi.org/10.5229/JECST.2016.7.4.306 rate charging and frequently leads to severe safety problems such as internal shorting by dendritic Li metal.

Ti-based oxides such as lithium titanate $\left(\mathrm{Li}_{4}\right.$ $\mathrm{Ti}_{5} \mathrm{O}_{12}$, LTO) [4-7] and titanium oxides $\left(\mathrm{TiO}_{2}\right)$ [8-10] have emerged as alternatives to graphite for negative electrode materials in high-power applications. Here, Li plating is unlikely even under high-current charging because their working potential $(1.5-1.8 \mathrm{~V}$ vs. $\left.\mathrm{Li} / \mathrm{Li}^{+}\right)$is much higher than that of Li metal. The high-current performance of $\mathrm{TiO}_{2}$ is, however, largely offset by the limited specific capacity $\left(<200 \mathrm{~mA} \mathrm{~h} \mathrm{~g}^{-1}\right)$. Their latent specific capacity cannot be fully utilized because of irreversible changes to inactive phases upon deep charging [11]. To prevent or mitigate the irreversible phase transitions, $\mathrm{TiO}_{2}$ 
has been prepared in nanostructured forms or amorphous phases. It is intuitive that phase transitions can be suppressed by introducing disorder, for instance, structural defects such as vacancies and void spaces on the surface of nanostructured materials or in the bulk of amorphous materials [12]. Moreover, nanostructuring of electrode materials is expected to be a promising strategy to increase the power density of cells by shortening the $\mathrm{Li}^{+}$diffusion path within the bulk materials [13-17]. In addition to suppressing unwanted phase transitions, amorphization of electrode materials has also been proven effective for increasing the number of $\mathrm{Li}^{+}$storage sites and facilitating solid-state $\mathrm{Li}^{+}$diffusion through the abundant void spaces [18-21]. The reason is very likely that the structural defects (vacancies and void spaces) can serve as $\mathrm{Li}^{+}$storage sites, as is well-known for hard carbons [22,23]. Recent studies have demonstrated that several amorphous materials can be successfully applied in $\mathrm{Na}^{+}$ion batteries because the amorphous framework provides $\mathrm{Na}^{+}$storage sites and ion diffusion channels [24,25].

A literature survey reveals that the rate performance of $\mathrm{TiO}_{2}$ electrodes can be improved somewhat by amorphization, but their specific capacity cannot be increased [18,26,27]. The capacity limitation can be understood by considering that lithiation proceeds via co-injection of $\mathrm{Li}^{+}$ions and the equivalent quantity of electrons. Electrode materials should carry both $\mathrm{Li}^{+}$storage sites and electron storage sites (redox centers). Even if the number of $\mathrm{Li}^{+}$storage sites (vacancies and void spaces) can be increased by amorphization of $\mathrm{TiO}_{2}$, the electron-accepting ability cannot be enlarged by amorphization because the redox centers are the metal $(\mathrm{Ti})$ ions in $\mathrm{TiO}_{2}$. In this work, to increase the specific capacity of amorphous $\mathrm{TiO}_{2}\left(a \mathrm{TiO}_{2}\right)$, a mixed oxide containing $\mathrm{Ti}$ and $\mathrm{V}$ ions was prepared on the basis of information in previous reports. As reported in a previous study, $\mathrm{V}^{5+}$ ions in amorphous $\mathrm{V}_{2} \mathrm{O}_{5}\left(a \mathrm{~V}_{2} \mathrm{O}_{5}\right)$ have better electron uptake than $\mathrm{Ti}^{4+}$ in $a \mathrm{TiO}_{2}$ at $>1.0 \mathrm{~V}[28-31]$. If this is the case in the mixed oxide prepared in this work, $\mathrm{V}^{5+}$ ions can show a higher electron-accepting ability as a redox center than $\mathrm{Ti}^{4+}$ ions; the net result will be an increase in the specific capacity. A further role of $\mathrm{V}^{5+}$ ions is that homogeneous mixing of $\mathrm{V}^{5+}$ and $\mathrm{Ti}^{4+}$ ions in the oxide matrix can produce a larger number of structural disorders that can act as $\mathrm{Li}^{+}$storage sites [32,33].
As a way to introduce $\mathrm{V}^{5+}$ ions into $a \mathrm{TiO}_{2}$, amorphous vanadium titanate ( $a$ VTO) was synthesized using a simple precipitation method. The following features of the synthesized $a \mathrm{VTO}$ were examined: (i) whether the $\mathrm{V}$ and $\mathrm{Ti}$ ions in $a \mathrm{VTO}$ are homogeneously mixed at an atomic scale instead of existing in a physical mixture of $a \mathrm{~V}_{2} \mathrm{O}_{5}$ and $a \mathrm{TiO}_{2}$, (ii) how the oxidation state of the $\mathrm{V}$ and $\mathrm{Ti}$ ions and the surrounding local structure in $a \mathrm{VTO}$ differ from those in their respective oxides $\left(a \mathrm{~V}_{2} \mathrm{O}_{5}\right.$ and $\left.a \mathrm{TiO}_{2}\right)$, and (iii) how the $\mathrm{Li}^{+}$storage sites and redox centers in $a \mathrm{VTO}$ differ from those in their respective oxides. Another objective of this work was to decrease the quantity of surface impurities such as surface hydroxyl groups and residual water, which are known to cause side reactions that lower the Coulombic efficiency and increase the electrode resistance [20,34,35]. In this work, the amorphous materials were synthesized by a precipitation method without heat treatment; a high population of surface hydroxyl groups and residual water was unavoidable. The effects of these impurities on the electrode performance of $a \mathrm{VTO}$ were examined. To avoid these impurities, the synthetic atmosphere was changed from air to nitrogen, and the effect of this change on the impurity levels and electrochemical performance was also examined.

\section{Experimental Section}

Amorphous vanadium titanates ( $a$ VTOs) were synthesized by a precipitation method. Vanadium oxide sulfate hydrate $\left(2.5 \mathrm{~g}, \mathrm{VOSO}_{4} \cdot x \mathrm{H}_{2} \mathrm{O}\right.$, Alfa Aesar) and titanium oxide sulfate sulfuric acid hydrate $(2.5 \mathrm{~g}$, $\mathrm{TiOSO}_{4} \cdot x \mathrm{H}_{2} \mathrm{O}+\mathrm{H}_{2} \mathrm{SO}_{4}$, Alfa Aesar) were dissolved in $250 \mathrm{~mL}$ of distilled water. Then, the precursor solution was dropped into a gas (air or nitrogen)purged urea solution to obtain precipitates [36]. The reaction temperature was fixed at $60^{\circ} \mathrm{C}$, and an ammonia solution was added dropwise to the solution to maintain the solution $\mathrm{pH}$ at 7 . The precipitates obtained under air and nitrogen atmospheres are denoted $a \mathrm{VTO}$ and $a \mathrm{VTO}-\mathrm{N}$, respectively. The resulting precipitates were centrifuged and washed with distilled water; this was followed by drying at $80^{\circ} \mathrm{C}$ overnight and additional drying at $300^{\circ} \mathrm{C}$ under vacuum for $2 \mathrm{~h}$. For comparison, amorphous vanadium pentoxide $\left(a \mathrm{~V}_{2} \mathrm{O}_{5}\right)$ and titanium oxide $\left(a \mathrm{TiO}_{2}\right)$ were also synthesized using the same procedure.

The particle morphology was examined using 
field-emission scanning electron microscopy (FESEM, JEOL JSM-6700F). Energy-dispersive X-ray spectroscopy (EDS) mapping was performed using a scanning transmission electron microscope (STEM, Tecnai F20). The surface area was measured from the nitrogen adsorption isotherm using a Micromeritics ASAP 2010 instrument. The X-ray diffraction (XRD) patterns were obtained using a Bruker D8 diffractometer equipped with $\mathrm{Cu} \mathrm{K} \alpha$ radiation (1.54056 $\AA$ ). The atomic ratio of titanium and vanadium in $a \mathrm{VTO}$ was measured by the inductively coupled plasma (ICP) technique using the Optima-4300 DV installed at the National Center for Inter-University Research Facilities at Seoul National University. X-ray absorption spectroscopy data for the titanium K-edge $\left(E_{0}=\right.$ $4966 \mathrm{eV})$ and vanadium K-edge $\left(E_{0}=5465.1 \mathrm{eV}\right)$ were obtained using transmission mode with a ring current of $320-400 \mathrm{~mA}$ at $3.0 \mathrm{GeV}$ at the Pohang Light Source. A Si (111) monochromator crystal was used with detuning to $70 \%$ in intensity to eliminate the high-order harmonics. Energy calibration for the titanium and vanadium K-edges was conducted using titanium and vanadium metal foil. Fourier transform infrared (FTIR) transmission spectra for $a \mathrm{VTO}$ and the reference oxides were measured using a Bruker Vertex $80 \mathrm{~V}$ IR spectrometer in vacuum. The samples for the transmission spectra were pelletized with potassium bromide $(\mathrm{KBr})$.

To prepare the composite electrodes, the synthesized metal oxides, Super-P, styrene-butadiene rubber (SBR), and carboxymethyl cellulose (CMC) (80:10:5:5 in weight ratio) were mixed in an agate mortar and dispersed in distilled water. The slurry was then coated on copper foil (LS wire, thickness $20 \mu \mathrm{m}$ ) with a doctor blade in a drying room. The composite electrodes were punched and dried at $120^{\circ} \mathrm{C}$ overnight in vacuum. The mass loading of active material in the electrodes was $1.6-2.0 \mathrm{mg} \mathrm{cm}^{-2}$. Coin cells (2032type) were fabricated in an argon-filled dry box. Lithium foil and a trilayered polypropylene-polyethylene membrane (PP-PE-PP, Celgard 2320) were used as the counter electrode and separator, respectively. $\mathrm{LiPF}_{6}(1.0 \mathrm{M})$ dissolved in ethylene carbonate and dimethyl carbonate (DMC) (1:2 in volume ratio) was used as the electrolyte. Galvanostatic charge/discharge measurements were performed at a current density of $100 \mathrm{~mA} \mathrm{~g}^{-1}$ over the potential range of 0.8 $3.0 \mathrm{~V}$ (vs. $\mathrm{Li} / \mathrm{Li}^{+}$). X-ray photoelectron spectroscopy (XPS) data were collected in an ultrahigh-vacuum multipurpose surface analysis system (Sigma Probe, Thermo Scientific, UK) operating at a base pressure of $<10^{-10}$ mbar. The photoelectrons were excited by an $\mathrm{Al} \mathrm{K} \alpha(1486.6 \mathrm{eV})$ anode operating at a constant power of $100 \mathrm{~W}(15 \mathrm{kV}$ and $10 \mathrm{~mA})$. For ex situ XPS analysis, $a$ VTO and $a$ VTO-N electrodes were prepared by embedding the powder in a copper foil to eliminate interference coming from the conductive carbon (Super-P) and the polymer binder (SBR$\mathrm{CMC}$ ). The cycled cells were disassembled, and the electrode samples were washed with DMC in an argon-filled glove box. They were then transferred to the XPS instrument without air exposure. The binding energy was calibrated from the hydrocarbon contamination using the $\mathrm{C} 1 \mathrm{~s}$ peak at $285.0 \mathrm{eV}$.

\section{Results and Discussion}

Fig. $1 \mathrm{a}$ and $1 \mathrm{~b}$ show FE-SEM images of the synthesized $a$ VTO powder. Its size was approximately
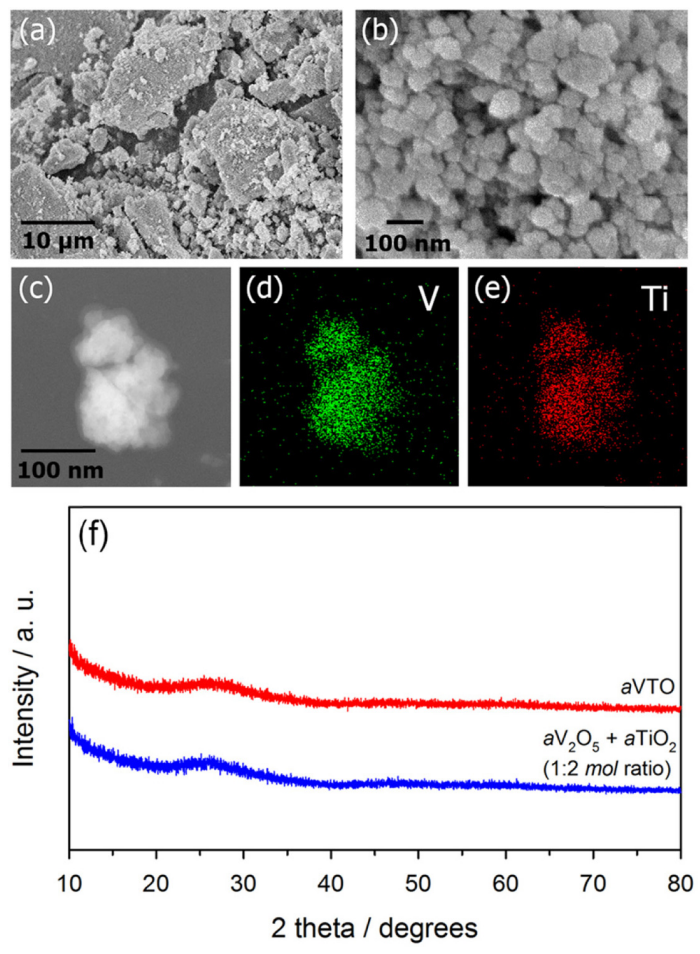

Fig. 1. (a) and (b) FE-SEM images of $a \mathrm{VTO}$, (c) STEM image of $a \mathrm{VTO}$, (d) and (e) EDS mappings of vanadium and titanium, and (f) XRD patterns of $a \mathrm{VTO}$ powder and $a \mathrm{~V}_{2} \mathrm{O}_{5}+a \mathrm{TiO}_{2}\left(1: 2\right.$ in mole ratio) powder dried at $300^{\circ} \mathrm{C}$ under vacuum. 
several microns, and it consisted of small primary particles $<100 \mathrm{~nm}$ in size, resulting in a large surface area of $54.39 \mathrm{~m}^{2} \mathrm{~g}^{-1}$. The morphology of $a$ VTO powder is advantageous in high-power applications because it provides a short $\mathrm{Li}^{+}$diffusion path and a larger contact area with the electrolyte solution [1317]. Fig. 1c-e show the STEM image and EDS mappings, which demonstrate that titanium and vanadium are homogeneously dispersed within the nanosized primary particles. The ICP measurement reveals that the atomic ratio of titanium and vanadium is close to $1: 1$. The XRD pattern obtained from the $a$ VTO pow-
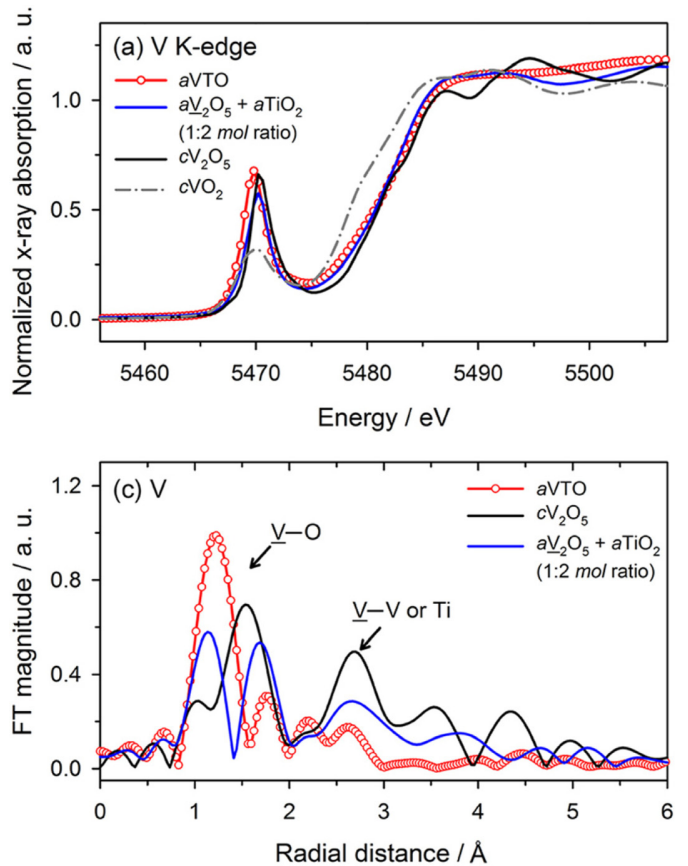

der was featureless, indicating the amorphous nature of the synthesized powder (Fig. 1f).

The metal valence and local structure of metal ions in $a \mathrm{VTO}, a \mathrm{~V}_{2} \mathrm{O}_{5}$, and $a \mathrm{TiO}_{2}$ were examined using $\mathrm{X}$ ray absorption near-edge structure (XANES) spectra (Fig. 2a and 2b) and extended X-ray absorption fine structure (EXAFS) spectra (Fig. 2c and 2d). The appearance of the main edge of vanadium, which is a common feature of crystalline vanadium pentoxide $\left(c \mathrm{~V}_{2} \mathrm{O}_{5}\right)$ [37], indicates that the vanadium valence is $5+$ for both $a \mathrm{VTO}$ and $a \mathrm{~V}_{2} \mathrm{O}_{5}$ (Fig. 2a). The titanium valence is $4+$ in both $a \mathrm{VTO}$ and $a \mathrm{TiO}_{2}$ because the
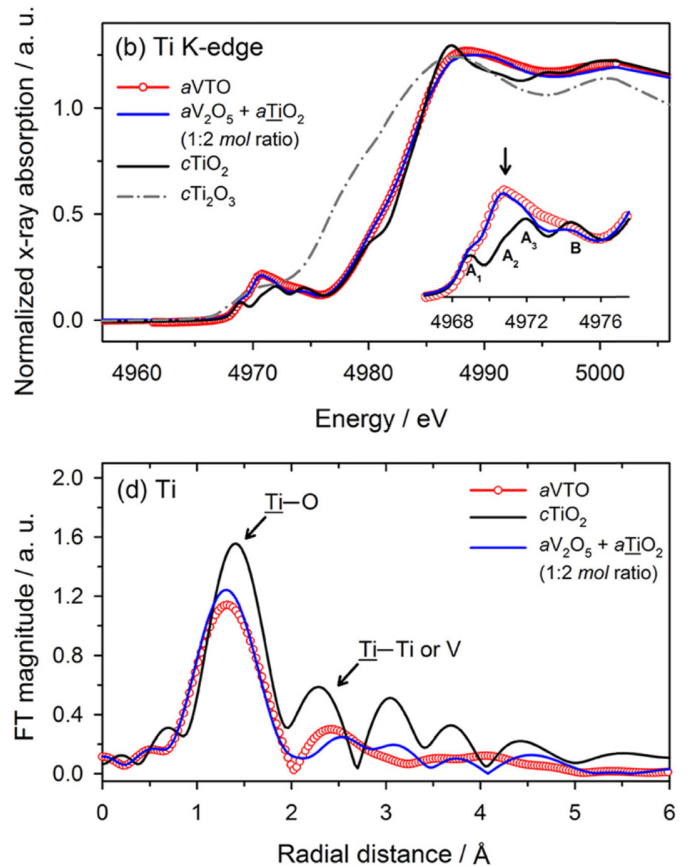

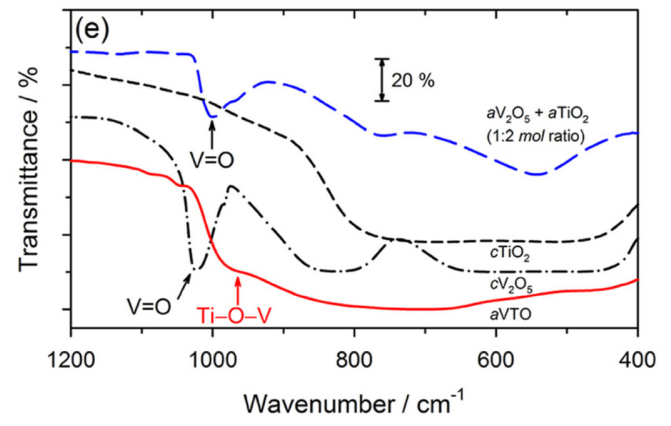

Fig. 2. XANES data for $a$ VTO and some reference oxides: (a) vanadium K-edge and (b) titanium K-edge. XANES data for : and $\mathrm{TiO}_{2}$ are taken from a physically mixed $a \mathrm{TiO}_{2}+a \mathrm{~V}_{2} \mathrm{O}_{5}$ electrode. Fourier transformed EXAFS data: (c) vanadium titanium K-edge for $a$ VTO and reference oxides. EXAFS data for amorphous $\mathrm{V}_{2} \mathrm{O}_{5}$ and $\mathrm{TiO}_{2}$ are taken from a physically $a \mathrm{~V}_{2} \mathrm{O}_{5}$ electrode. (e) FTIR spectra measured in vacuum for $\mathrm{KBr}$-pelletized $a \mathrm{VTO}, c \mathrm{~V}_{2} \mathrm{O}_{5}, c \mathrm{TiO}_{2}$, and a physical mixture of $a^{\prime}$ 
main edge appears as it does for crystalline titanium oxide $\left(c \mathrm{TiO}_{2}\right)$, which also has a Ti valence of $4+$. The local structure of $\mathrm{V}^{5+}$ in $a \mathrm{VTO}$ and $a \mathrm{~V}_{2} \mathrm{O}_{5}$ was analyzed using the data shown in Fig. $2 \mathrm{a}$ and $2 \mathrm{c}$. The pre-edge of the vanadium K-edge does not appear if the local symmetry of $\mathrm{V}^{5+}$ is octahedral. With a decrease in the local symmetry from an octahedral geometry, the pre-edge of the vanadium K-edge becomes stronger owing to a formally forbidden dipole transition from the vanadium 1s orbital to oxygen $2 p$ states hybridized with $3 \mathrm{~d}$ orbitals [22]. As shown in Fig. $2 \mathrm{a}$, the orthorhombic $\mathrm{V}_{2} \mathrm{O}_{5}\left(c \mathrm{~V}_{2} \mathrm{O}_{5}\right)$ shows a strong pre-edge because vanadium ions are located at the five-coordinate $\left(\mathrm{VO}_{5}\right)$ square pyramidal sites [29], which exhibit much lower symmetry than the six-coordinate octahedral structure. This strong pre-edge peak is also observed in both $a \mathrm{~V}_{2} \mathrm{O}_{5}$ and $a \mathrm{VTO}$, implying that the local structure of $\mathrm{V}^{5+}$ is not octahedral. The detailed local structure can be estimated from the $\mathrm{V}-\mathrm{O}$ shell depicted in Fig. 2c. The $\mathrm{V}-\mathrm{O}$ peak of orthorhombic $\mathrm{V}_{2} \mathrm{O}_{5}\left(c \mathrm{~V}_{2} \mathrm{O}_{5}\right)$ has low intensity and is divided into two (black line), which must be due to the fact that the V-O shell is composed of one short $\mathrm{V}=\mathrm{O}$ bond $(1.07 \AA)$ and four long $\mathrm{V}-\mathrm{O}$ bonds $(1.53 \AA)$ (five-coordinate square pyramidal sites, as shown in Fig. 2a). $a \mathrm{~V}_{2} \mathrm{O}_{5}$ also shows a similar $\mathrm{V}-\mathrm{O}$ shell comprising a short $\mathrm{V}=\mathrm{O}$ bond and long $\mathrm{V}-\mathrm{O}$ bonds, although the former is more intense than the latter (blue line), illustrating that the local structure of $\mathrm{V}^{5+}$ in $a \mathrm{~V}_{2} \mathrm{O}_{5}$ does not differ greatly from that in $c \mathrm{~V}_{2} \mathrm{O}_{5}$ (five-coordinate). However, the local structure of $\mathrm{V}^{5+}$ in $a \mathrm{VTO}$ is not five-coordinate, as demonstrated by the EXAFS data in Fig. 2c. Namely, the V$O$ shell produces an intensified single peak (red) at $1.20 \AA$, which corresponds to a tetrahedral structure around the $\mathrm{V}^{5+}$ ions [38]. The difference in $\mathrm{V}^{5+}$ local structure between $a \mathrm{VTO}$ (four-coordinate) and $a \mathrm{~V}_{2} \mathrm{O}_{5}$ (five-coordinate) indicates that $a \mathrm{VTO}$ is not a physical mixture of $a \mathrm{~V}_{2} \mathrm{O}_{5}$ and $a \mathrm{TiO}_{2}$; rather, the $\mathrm{V}^{5+}$ and $\mathrm{Ti}^{4+}$ ions are homogeneously mixed at the atomic scale. The local structure modification and homogeneous atomic scale mixing of $\mathrm{V}^{5+}$ can also be observed in the FTIR spectrum of $a$ VTO (Fig. 2e). A sharp peak at about $995-1028 \mathrm{~cm}^{-1}$, indicative of a V $=\mathrm{O}$ bond, was significantly reduced. A broad shoulder between 950 and $980 \mathrm{~cm}^{-1}$, which is known to indicate the Ti-O-V bond, strongly implies chemical interaction between $\mathrm{V}^{5+}$ and $\mathrm{Ti}^{4+}[39]$.

The local structure of $\mathrm{Ti}^{4+}$ in $a \mathrm{VTO}$ and $a \mathrm{TiO}_{2}$ was also analyzed. The titanium pre-edge peaks from crystalline (anatase) $\mathrm{TiO}_{2}\left(c \mathrm{TiO}_{2}\right)$ appear at 4969.2, 4970.8, 4972.0, and $4974.4 \mathrm{eV}$ and are labeled $\mathrm{A}_{1}, \mathrm{~A}_{2}$, $A_{3}$, and $B$, respectively, as shown in the inset of Fig. $2 b$ [40]. The first three $\left(A_{1}, A_{2}\right.$, and $\left.A_{3}\right)$ are due to dipole transitions to titanium $4 p$ states hybridized with titanium $3 \mathrm{~d}$ orbitals that are split into the $\mathrm{t}_{2 \mathrm{~g}}$ and $\mathrm{e}_{\mathrm{g}}$ bands, respectively [40]. As shown in Fig. 2b, the $A_{2}$ and $A_{3}$ peaks of $a \mathrm{TiO}_{2}$ and $a \mathrm{VTO}$ are much stronger than those of $c \mathrm{TiO}_{2}$, implying that the regular $\mathrm{TiO}_{6}$ octahedron, which is dominant in anatase $\mathrm{TiO}_{2}$, is distorted to form an irregular fivefold coordination $\left(\mathrm{TiO}_{5}\right)$ structure in both $a \mathrm{TiO}_{2}$ and $a \mathrm{VTO}[18,41,42]$. This feature can be ascertained from the radial distribution obtained from the Fourier transformation of the EXAFS spectra shown in Fig. 2d. The Ti-O bond in $c \mathrm{TiO}_{2}$ is located at $1.41 \AA$, but this peak is shifted to $1.35 \AA$ for $a \mathrm{TiO}_{2}$ and $a$ VTO. This observation agrees with the XANES spectra, which suggest irregular fivefold coordination of $\mathrm{Ti}^{4+}$ in $a \mathrm{TiO}_{2}$ and $a \mathrm{VTO}$ (Fig. 2b). That is, the Ti-O bond length is shorter for five-coordinate structures ( $a \mathrm{TiO}_{2}$ and $a \mathrm{VTO}$ ) than for the six-coordinate structure $\left(c \mathrm{TiO}_{2}\right)$. In short, it is found that $a \mathrm{VTO}$ is composed of homogeneous mixing of irregular $\mathrm{TiO}_{5}$ and tetrahedral $\mathrm{VO}_{4}$ at the atomic scale rather than a physical mixture of the two separate oxides.

The galvanostatic lithiation and delithiation voltage profiles of the Li/aVTO cell are shown in Fig. $3 \mathrm{a}$. The $a$ VTO electrode shows a sloping voltage profile, which is a characteristic feature of amorphous electrodes, and exhibits a reversible capacity of $295 \mathrm{~mA} \mathrm{~h} \mathrm{~g}^{-1}$ in the first cycle. Note that this value is much larger than those of LTO $\left(175 \mathrm{~mA} \mathrm{~h} \mathrm{~g}^{-1}\right)$, anatase $\mathrm{TiO}_{2}\left(168 \mathrm{~mA} \mathrm{~h} \mathrm{~g}^{-1}\right)$, and even amorphous $\mathrm{TiO}_{2}$, which shows a slightly larger capacity than anatase $\mathrm{TiO}_{2}$ (Fig. 3d) [7,43]. The electrode consisting of mechanically mixed $a \mathrm{~V}_{2} \mathrm{O}_{5}$ and $a \mathrm{TiO}_{2}$, which were mixed in a 1:2 mole ratio to simulate the atomic ratio (1:1) in $a$ VTO, delivers a reversible capacity of $245 \mathrm{~mA} \mathrm{~h} \mathrm{~g}^{-1}$ in the first cycle (Fig. 3c). Note that the reversible capacity of the $a \mathrm{VTO}$ electrode is larger than that of the mixed electrode, and the voltage profiles of the two are different in the first lithiation.

The redox behaviors of the two redox centers ( $\mathrm{V}$ and $\mathrm{Ti}$ ) in the $a \mathrm{VTO}$ and $a \mathrm{~V}_{2} \mathrm{O}_{5}+a \mathrm{TiO}_{2}$ electrodes were compared using ex situ XANES spectra (Fig. 4a and $4 \mathrm{~b}$ ). To obtain the relationship between the metal valence and absorption energy, XANES data were obtained from some reference oxides, namely, crys- 

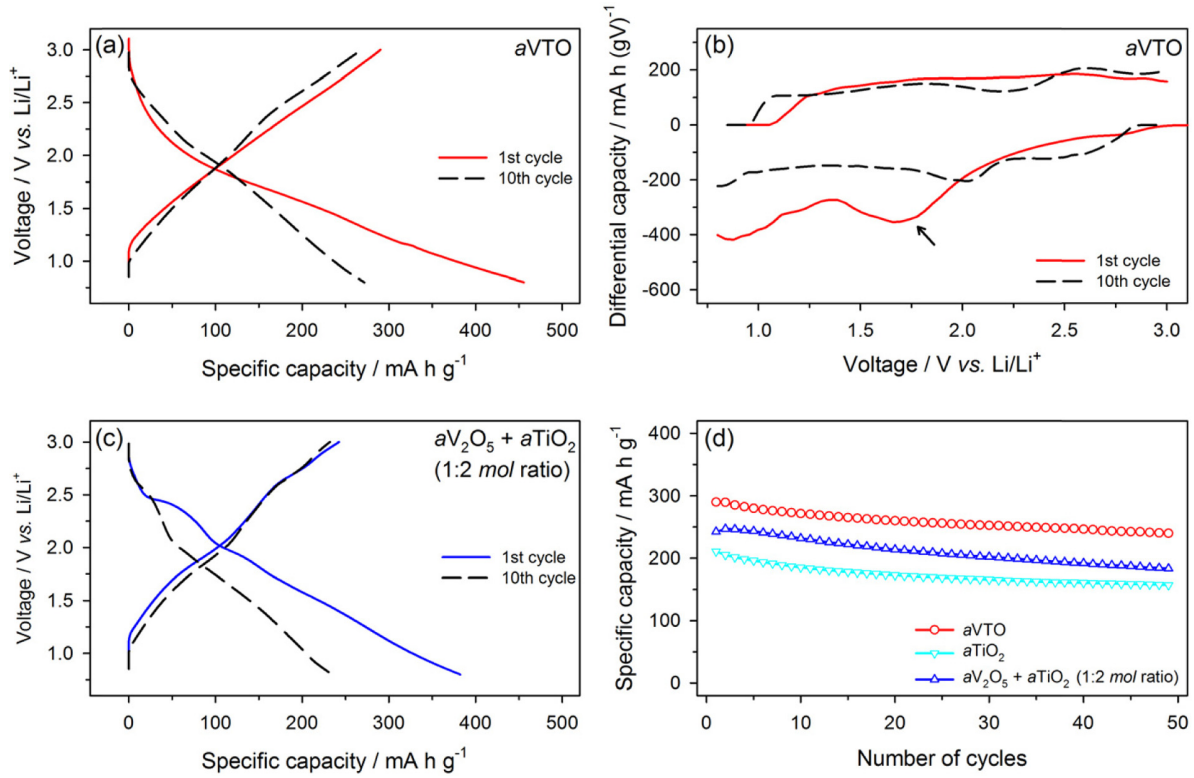

Fig. 3. (a) Lithiation/delithiation voltage profile obtained from $\mathrm{Li} / \mathrm{aVTO}$ cell, (b) differential capacity plot derived from (a), (c) lithiation/delithiation voltage profile obtained from $\mathrm{Li} / a \mathrm{~V}_{2} \mathrm{O}_{5}+a \mathrm{TiO}_{2}$ (physical mixture in 1:2 mole ratio) cell, and (d) cycle performance of $\mathrm{Li} / a \mathrm{VTO}, \mathrm{Li} / a \mathrm{TiO}_{2}$, and $\mathrm{Li} / a \mathrm{~V}_{2} \mathrm{O}_{5}+a \mathrm{TiO}_{2}$ cells.
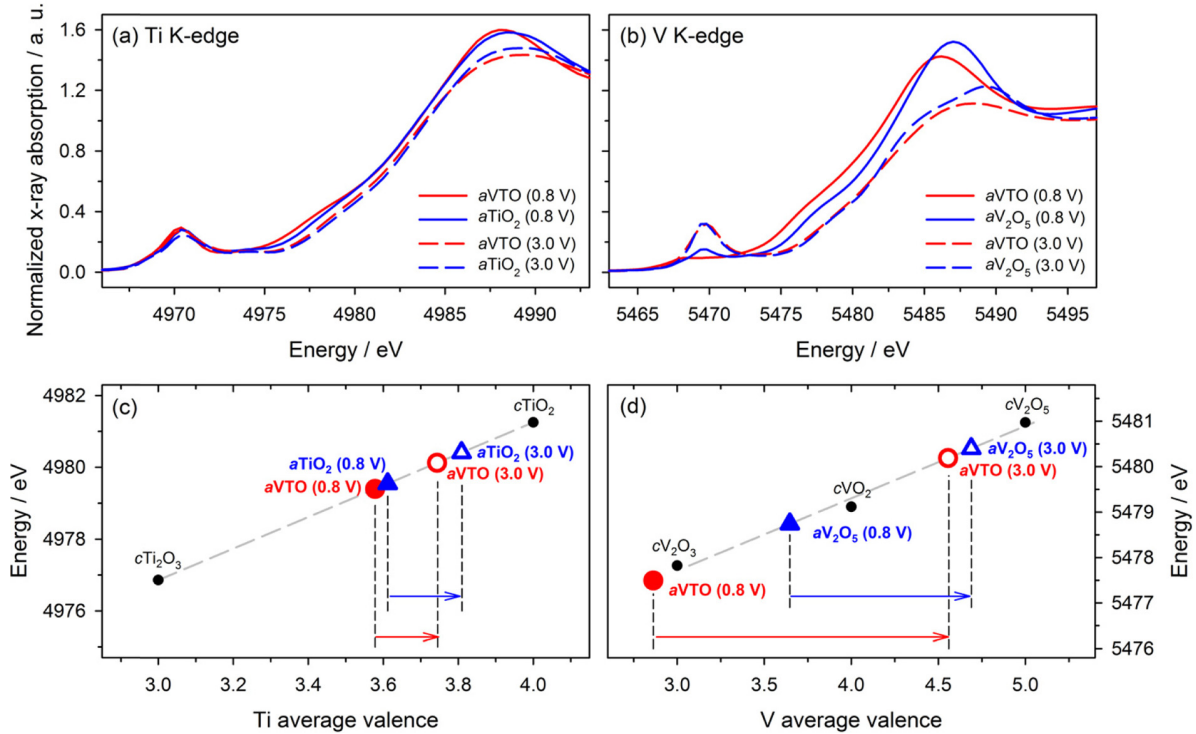

Fig. 4. Ex situ XANES spectra of (a) Ti K-edge and (b) V K-edge for $a \mathrm{VTO}, a \mathrm{TiO}_{2}$, and $a \mathrm{~V}_{2} \mathrm{O}_{5}$ electrodes, which were obtained in the fully lithiated state $\left(0.8 \mathrm{~V}\right.$ vs. $\left.\mathrm{Li} / \mathrm{Li}^{+}\right)$and fully delithiated state $(3.0 \mathrm{~V})$ in the first cycle. Metal valence changes for (c) Ti and (d) V upon the first lithiation, which were estimated from (a) and (b), respectively.

talline titanium oxides $\left(c \mathrm{TiO}_{2}\right.$ and $\left.c \mathrm{Ti}_{2} \mathrm{O}_{3}\right)$ and vanadium oxides $\left(c \mathrm{~V}_{2} \mathrm{O}_{5}, c \mathrm{VO}_{2}\right.$, and $\left.c \mathrm{~V}_{2} \mathrm{O}_{3}\right)$, the metal valence of which has a formal value (for example, 4+ for $c \mathrm{TiO}_{2}$ and $\left.c \mathrm{VO}_{2}\right)$. The valence of the transition metal ions was calculated assuming that the metal valence is linearly related to the position of the main absorption edge. The electron energy at the halfheight of the main absorption edge was taken and 
plotted, along with the estimated metal valences of the reference oxides. Note that the shape and position of the main edge depend on not only the metal valence but also the local structure and coordination of metal ions, such that the calculated values carry an appreciable uncertainty. As shown in Fig. 4c, the Ti valence in $a$ VTO changes from $3.58+$ to $3.74+$. A comparable change is observed for $a \mathrm{TiO}_{2}$ (from $3.61+$ to $3.81+$ ), illustrating that the electron-accepting ability of Ti ions is comparable for $a \mathrm{VTO}$ and $a \mathrm{TiO}_{2}$. The redox behavior of $\mathrm{V}$ ions in $a \mathrm{VTO}$ and $a \mathrm{~V}_{2} \mathrm{O}_{5}$ was also examined. As shown in Fig. $4 \mathrm{~d}$, the $\mathrm{V}$ valence in $a \mathrm{VTO}$ changes from $2.7+$ to $4.6+$, whereas it changes from $3.6+$ to $4.7+$ in $a \mathrm{~V}_{2} \mathrm{O}_{5}$. Clearly, the oxidation state of $\mathrm{V}$ ions in $a \mathrm{VTO}$ is lower $(2.7+)$ that that in $a \mathrm{~V}_{2} \mathrm{O}_{5}(3.6+)$ upon lithiation, illustrating that the electron-accepting ability of $\mathrm{V}^{5+}$ ions as a redox center is greater in $a \mathrm{VTO}$. As shown in Fig. $3 \mathrm{a}$ and $3 \mathrm{c}$, the first reversible specific capacity of $a$ VTO (295 $\left.\mathrm{mA} \mathrm{h} \mathrm{g}^{-1}\right)$ is larger than that of the physically mixed oxide $\left(a \mathrm{~V}_{2} \mathrm{O}_{5}+a \mathrm{TiO}_{2}\right)\left(245 \mathrm{~mA} \mathrm{~h} \mathrm{~g}^{-1}\right)$. Hence, the extra capacity (ca. $50 \mathrm{~mA} \mathrm{~h} \mathrm{~g}^{-1}$ ) delivered by $a$ VTO can be attributed to the higher electronaccepting ability of the $\mathrm{V}^{5+}$ ions in $a \mathrm{VTO}$. The apparent difference between $a \mathrm{VTO}$ and $a \mathrm{~V}_{2} \mathrm{O}_{5}$ is due to the local structure; the $\mathrm{V}^{5+}$ ions in $a \mathrm{VTO}$ are four-coordinate, but those in $a \mathrm{~V}_{2} \mathrm{O}_{5}$ are five-coordinate. The experimental data suggest that the difference in the local structure of the $\mathrm{V}^{5+}$ ions can cause different redox behavior.

The extra capacity delivered by $a$ VTO can also be explained in another way. Namely, $a$ VTO should carry both $\mathrm{Li}^{+}$storage sites and redox centers for lithiation. Two possibilities exist. First, if $a$ VTO has abundant $\mathrm{Li}^{+}$storage sites (structural defects), which is likely because it is amorphous, the number of redox centers (number of electrons to be stored) determines the overall Li storage capacity. If this is the case, the changes in the electronic structure of $a \mathrm{VTO}$, which can be caused by modification of the local geometry by homogeneous mixing of cations, can change the Li storage capacity. One example is the $\mathrm{Co}^{3+}$ ions in the spinel-structured $\mathrm{LiMn}_{2-\mathrm{x}} \mathrm{Co}_{\mathrm{x}} \mathrm{O}_{4}$ and layered $\mathrm{LiCoO}_{2}$. Both the redox potential and redox capacity of $\mathrm{Co}^{3+}$ ions are different in the two oxides [44]. Considering that Ti substitution in $\mathrm{V}_{2} \mathrm{O}_{5}$ can alter the electronic structure of its original framework $[45,46]$, it is very likely that the $\mathrm{V}$ ions in the V-Ti-O structure have a different redox behavior from those in $\mathrm{V}_{2} \mathrm{O}_{5}$. However, because it is difficult to analyze the band structure of amorphous materials, it is still unclear why the V ions in $a$ VTO show a higher electron-accepting ability. The second possibility is the reverse case. Here, if the number of $\mathrm{Li}^{+}$ storage sites is smaller than that of redox centers, the overall capacity is determined by the former. If this is the case in $a \mathrm{VTO}$, the larger specific capacity of $a \mathrm{VTO}$ over the mixed electrode $\left(a \mathrm{~V}_{2} \mathrm{O}_{5}+a \mathrm{TiO}_{2}\right)$ can be accounted for by the generation of extra $\mathrm{Li}^{+}$storage sites (structural defects) resulting from the addition of $\mathrm{V}^{5+}$ ions to the $a \mathrm{TiO}_{2}$ matrix. This possibility has been proposed in previous studies [32,33].

As shown in Fig. $3 \mathrm{a}$ and $3 \mathrm{~b}$, the $\mathrm{Li} / \mathrm{aVTO}$ cell shows a large irreversible capacity in the first cycle, which diminishes in subsequent cycles. The major irreversible reactions occur at $<2.0 \mathrm{~V}$, as indicated by an arrow in Fig. 3b. Two possibilities exist for the irreversible reactions: electrolyte decomposition and $\mathrm{Li}$ reaction with residual water or surface hydroxyl groups. The former possibility is discarded because electrolyte decomposition is commonly observed at 0.7-0.8 V (vs. $\mathrm{Li} / \mathrm{Li}^{+}$). The latter possibility seems more probable because the amorphous samples can carry residual water and surface hydroxyl groups, as they were prepared by drying at $300^{\circ} \mathrm{C}$ under vacuum. Two irreversible reactions (Eqns. 1 and 2) can be assumed [34,35]:

$$
\begin{aligned}
& \mathrm{H}_{2} \mathrm{O}+2 \mathrm{Li}^{+}+2 \mathrm{e}^{-} \rightarrow \mathrm{LiOH}+\frac{1}{2} \mathrm{H}_{2}+\mathrm{Li}^{+}+\mathrm{e}^{-} \\
& \rightarrow \mathrm{Li}_{2} \mathrm{O}+\mathrm{H}_{2} \\
& \mathrm{OH}+2 \mathrm{Li}^{+}+2 \mathrm{e}^{-} \rightarrow \mathrm{LiOH}+\mathrm{Li}^{+}+\mathrm{e}^{-} \\
& \rightarrow \mathrm{Li}_{2} \mathrm{O}+\frac{1}{2} \mathrm{H}_{2}
\end{aligned}
$$

This is validated by the XPS spectra obtained from the $a \mathrm{VTO}$ electrode before and after lithiation (Fig. $5 \mathrm{a}$ and $5 \mathrm{~b}$ ). The $\mathrm{O} 1 \mathrm{~s}$ spectra obtained before lithiation were deconvoluted into three peaks. The peak at $530.7 \mathrm{eV}$ corresponds to the bulk oxygen in amorphous metal oxides. The $\mathrm{O} 1 \mathrm{~s}$ photoelectrons at 532.7 and $534.0 \mathrm{eV}$ come from the oxygen in hydroxyl groups and adsorbed water on the metal oxide surface, respectively [47]. As shown in Fig. 5a, the surface of $a \mathrm{VTO}$ is covered with hydroxyl groups. The four peaks in the $\mathrm{O} 1 \mathrm{~s}$ spectra obtained after lithiation were assigned according to the reported binding energies: $\mathrm{Li}_{2} \mathrm{O}$ at $528.5 \mathrm{eV}, \mathrm{LiOH}$ at $531.5 \mathrm{eV}, \mathrm{Li}_{2} \mathrm{CO}_{3}$ and 
oxygen atoms doubly bound to carbon atoms at 532 $\mathrm{eV}$, and oxygen bound to carbon with a single bond at $533.5 \mathrm{eV}[48,49]$. A large amount of $\mathrm{Li}_{2} \mathrm{O}$ and $\mathrm{LiOH}$ is found on the surface of lithiated $a$ VTO. Clearly, the surface hydroxyl groups and residual water in $a \mathrm{VTO}$ are converted into $\mathrm{Li}_{2} \mathrm{O}$ and $\mathrm{LiOH}$ according to Eqns. 1 and 2, which appear as the irreversible capacity in Fig. $3 a$ and $3 b$.
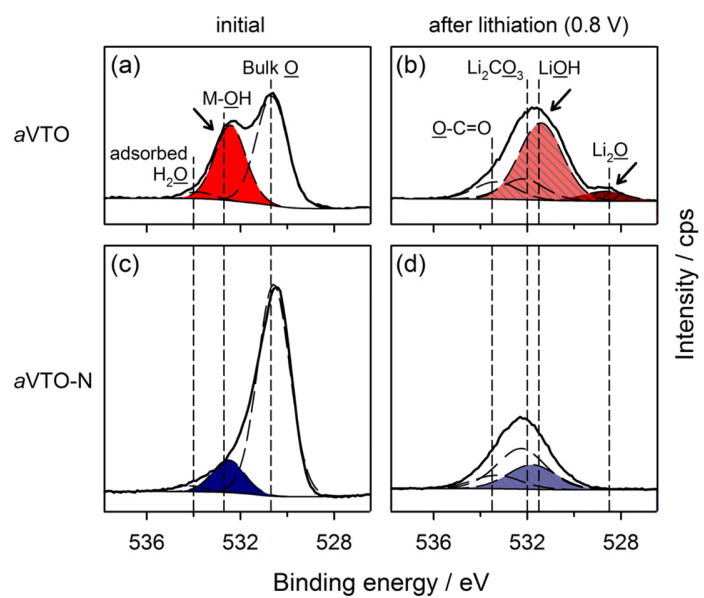

Fig. 5. O 1s XPS spectra: (a) $a \mathrm{VTO}$ in the initial opencircuit voltage (OCV) state, (b) $a \mathrm{VTO}$ after lithiation down to $0.8 \mathrm{~V}$, (c) $a \mathrm{VTO}-\mathrm{N}$ in the initial OCV state, and (d) $a$ VTO-N after lithiation down to $0.8 \mathrm{~V}$.

(a)

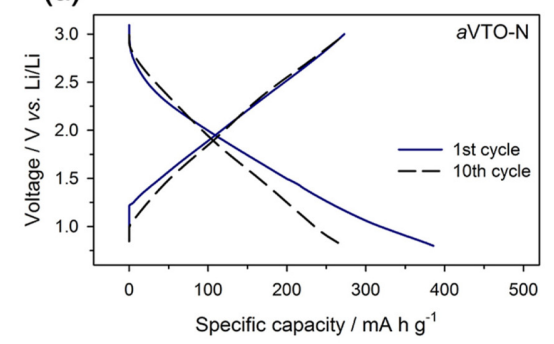

(c)

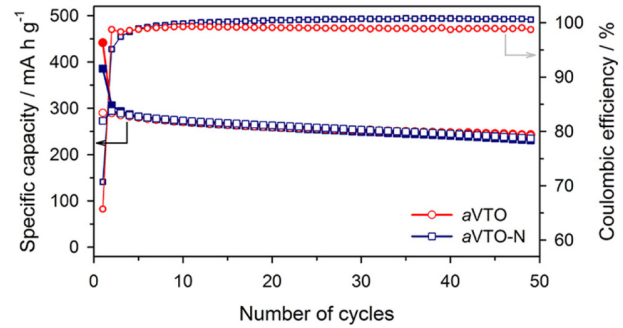

Fig. 5c displays the O 1s XPS spectra obtained from the pristine $a$ VTO-N electrode. The major O $1 \mathrm{~s}$ photoelectrons are emitted from the lattice (bulk) oxygen. The population of surface hydroxyl groups and adsorbed water is much smaller than that in $a$ VTO. The only difference between the two samples is the synthetic atmosphere (air and nitrogen). It is curious that more surface hydroxyl groups form in the presence of excess oxygen. The following reaction is proposed. Molecular oxygen can be converted into lattice oxygen, accompanied by generation of metal vacancies and holes as described by Eqn. 3. In the presence of water, the lattice oxygen and holes react further with water to generate surface hydroxyl groups as shown in Eqn. 4 [50].

$$
\begin{aligned}
& \frac{9}{2} \mathrm{O}_{2} \rightarrow 2 V_{\mathrm{Ti}}^{\prime \prime \prime \prime}+2 V_{\mathrm{V}}^{\prime \prime \prime \prime}+9 \mathrm{O}_{\mathrm{O}}^{\mathrm{x}}+18 \mathrm{~h} \\
& 2 V_{\mathrm{Ti}}^{\prime \prime \prime \prime}+2 V_{\mathrm{V}}^{\prime \prime \prime \prime \prime}+9 \mathrm{O}_{\mathrm{O}}^{\mathrm{x}}+18 \mathrm{~h}+9 \mathrm{H}_{2} \mathrm{O} \\
& \rightarrow 2 V_{\mathrm{Ti}}^{\prime \prime \prime}+2 V_{\mathrm{V}}^{\prime \prime \prime \prime}+18 \mathrm{OH}_{\mathrm{O}}^{\circ}
\end{aligned}
$$

If this is the case, the reduced population of surface hydroxyl groups on $a \mathrm{VTO}-\mathrm{N}$ can be rationalized.

The morphology and bulk properties of $a$ VTO-N are very similar to those of $a \mathrm{VTO}$ even though $a$ VTO-N has a larger surface area $\left(62.77 \mathrm{~m}^{2} \mathrm{~g}^{-1}\right)$. The

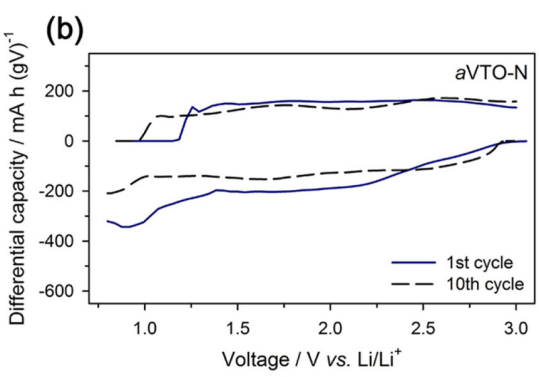

(d)

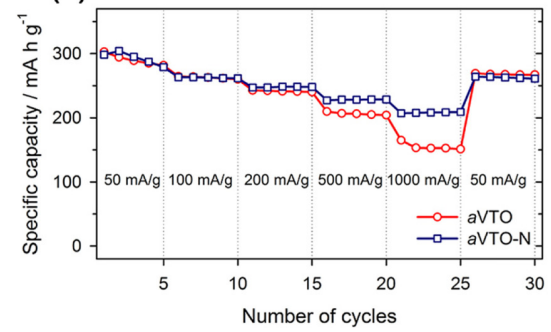

Fig. 6. (a) Lithiation/delithiation voltage profile obtained from the Li/aVTO-N cell, (b) differential capacity plot derived from (a), (c) comparison of the cycle data and Coulombic efficiency of $a$ VTO and $a$ VTO-N, and (d) rate performance of $a \mathrm{VTO}$ and $a \mathrm{VTO}-\mathrm{N}$ electrodes. 
metal valence is not changed even when the reaction atmosphere is changed from air to nitrogen. As shown in Fig. 6a, the electrode performance of the Li/ $a$ VTO-N cell, including the reversible capacity and cycling ability, is also comparable to that of $\mathrm{Li} / a \mathrm{VTO}$. The notable difference is the irreversible capacity in the first cycle. The irreversible capacity observed at $<2.0 \mathrm{~V}$ in the $a \mathrm{VTO}$ electrode (Fig. $3 \mathrm{~b}$ ) is notably diminished in the $a$ VTO-N electrode (Fig. 6b). As a result, the initial Coulombic efficiency increases in the $\mathrm{Li} / a$ VTO-N cell, as shown in Fig. 6c. Furthermore, the $\mathrm{Li} / a$ VTO-N cell shows higher Coulombic efficiency during cycling, indicating that the decreased quantity of surface hydroxyl groups positively affects the side reactions even after the first cycle.

The $\mathrm{Li} / a \mathrm{VTO}-\mathrm{N}$ cell outperforms the $\mathrm{Li} / a \mathrm{VTO}$ cell with respect to the rate capability (Fig. 6d). As pointed out above, the only difference between the two electrodes is the quantity of surface hydroxyl groups; thus, the difference in rate capability should be explained on the basis of the quantity of surface hydroxyl groups. As shown in Fig. 5d, the quantity of inorganic components such as $\mathrm{Li}_{2} \mathrm{O}$ and $\mathrm{LiOH}$, which are known to impede $\mathrm{Li}^{+}$diffusion [51], is greatly diminished on the $a$ VTO-N electrode. This must be due to the lower quantity of surface hydroxyl groups on $a$ VTO-N. As a result, the formation of highly resistive inorganic compounds $\left(\mathrm{Li}_{2} \mathrm{O}\right.$ and $\left.\mathrm{LiOH}\right)$ is greatly suppressed during cell cycling. In short, a lower population of surface hydroxyl groups on $a \mathrm{VTO}-\mathrm{N}$ is responsible for the decrease in irreversible capacity and the enhanced rate capability of the $\mathrm{Li} / a \mathrm{VTO}-\mathrm{N}$ cell.

\section{Conclusions}

To increase the specific capacity of amorphous titanium dioxide $\left(a \mathrm{TiO}_{2}\right)$ electrodes, which are known to exhibit a reasonable rate capability, $\mathrm{V}^{5+}$ ions were incorporated into the $a \mathrm{TiO}_{2}$ matrix. The physicochemical properties and electrode performance of the resulting amorphous vanadium titanates ( $a$ VTOs) are summarized as follows.

(i) The prepared samples were not a physical mixture of $a \mathrm{~V}_{2} \mathrm{O}_{5}$ and $a \mathrm{TiO}_{2}$. The $\mathrm{V}^{5+}$ and $\mathrm{Ti}^{4+}$ ions were homogeneously dispersed in the amorphous oxide matrix at the atomic scale.

(ii) The $\mathrm{V}^{5+}$ ions in $a \mathrm{VTO}$ were at four-coordinate sites, in contrast to the five-coordinate $\mathrm{V}^{5+}$ ions in $a \mathrm{~V}_{2} \mathrm{O}_{5}$. However, fivefold coordination of $\mathrm{Ti}^{4+}$ ions appeared for $a \mathrm{TiO}_{2}$ and $a$ VTO.

(iii) The oxide electrodes showed a sloping charge/ discharge voltage profile, which is a characteristic feature of amorphous electrodes. $\mathrm{Li}^{+}$storage in structural defects (vacancies, void spaces, cluster gaps, or interstitial sites) can thus be assumed.

(iv) The reversible specific capacity of $a$ VTO was larger than that of the physically mixed $\left(a \mathrm{~V}_{2} \mathrm{O}_{5}\right.$ and $a \mathrm{TiO}_{2}$ in stoichiometric ratio) electrode. The extra capacity delivered by $a \mathrm{VTO}$ was thus attributed to contributions from the fourfold-coordinated $\mathrm{V}^{5+}$ ions in $a$ VTO. Two possibilities were proposed for this contribution. One is the modification of the electronic structure by a local geometric change of $\mathrm{V}$ ions in $a$ VTO. The other is the creation of extra $\mathrm{Li}^{+}$storage sites (structural defects) by the incorporation of $\mathrm{V}^{5+}$ ions into the $a \mathrm{TiO}_{2}$ matrix.

(v) The surface hydroxyl groups and residual water in $a$ VTO caused a serious irreversible reaction and formation of highly resistive inorganic species. The impurity population was, however, greatly reduced by changing the synthetic atmosphere from air to nitrogen. The amorphous vanadium titanate prepared under nitrogen $(a \mathrm{VTO}-\mathrm{N})$ outperformed that prepared under air in terms of the Coulombic efficiency and rate capability.

\section{Acknowledgments}

We acknowledge financial support from the National Research Foundation of Korea funded by the Ministry of Education, Science \& Technology (MEST) (Grant NRF-2010- C1AAA001-20100029065). We thank the staff of the Research Institute of Advanced Materials (RIAM) for assistance with the STEM and EDS experiments.

\section{References}

[1] M. Winter, J.O. Besenhard, M.E. Spahr, P. Novák, $A d v$. Mater, 1998, 10(10), 725-763.

[2] J.-M. Tarascon, M. Armand, Nature., 2001, 414(6861), 359-367.

[3] T.H. Kim, J.S. Park, S.K. Chang, S. Choi, J.H. Ryu, H.K. Song, Adv. Energy Mater, 2012, 2(7), 860-872.

[4] T. Ohzuku, T. Kodama, T. Hirai, J. Power Sources., 1985, 14(1), 153-166.

[5] K.M. Colbow, J.R. Dahn, R.R. Haering, J. Power Sources., 1989, 26(3-4), 397-402. 
[6] T. Ohzuku, J. Electrochem. Soc., 1995, 142(5), 14311435.

[7] R. Inada, K. Shibukawa, C. Masada, Y. Nakanishi, Y. Sakurai, J. Power Sources., 2014, 253, 181-186.

[8] L. Kavan, K. Kratochvilová, M. Grätzel, J. Electroanal. Chem., 1995, 394(1), 93-102.

[9] L. Kavan, M. Grätzel, J. Rathouskýb, A. Zukalba, J. Electrochem. Soc., 1996, 143(2), 394-400.

[10] M.S. Balogun, C. Li, Y. Zeng, M. Yu, Q. Wu, M. Wu, X. Lu, Y. Tong, J. Power Sources., 2014, 272, 946-953.

[11] U. Lafont, C. D., G. Mountjoy, A. V. Chadwick, E.M. Kelder, J. Phys. Chem. C., 2010, 114(2), 1372-1378.

[12] M. Wagemaker, W.J.H. Borghols, E.R.H. Van Eck, A.P.M. Kentgens, G.J. Kearley, F.M. Mulder, Chem. - A Eur. J., 2007, 13(7), 2023-2028.

[13] J.S. Chen, X.W. Lou, J. Power Sources., 2010, 195(9), 2905-2908

[14] Y. Ren, Z. Liu, F. Pourpoint, A.R. Armstrong, C.P. Grey, P.G. Bruce, Angew. Chemie - Int. Ed., 2012, 51(9), 21642167.

[15] Q. Wu, J. Xu, X. Yang, F. Lu, S. He, J. Yang, H.J. Fan, M. Wu, Adv. Energy Mater, 2015, 5, 1401756.

[16] W. Li, F. Wang, Y. Liu, J. Wang, J. Yang, L. Zhang, A.A. Elzatahry, D. Al-Dahyan, Y. Xia, D. Zhao, Nano Lett., 2015, 15(3), 2186-2193.

[17] H. Liu, W. Li, D. Shen, D. Zhao, G. Wang, J. Am. Chem. Soc., 2015, 137(40), 13161-13166.

[18] W.J.H. Borghols, D. Lu?tzenkirchen-Hecht, U. Haake, W. Chan, U. Lafont, E.M. Kelder, E.R.H. van Eck, A.P.M. Kentgens, F.M. Mulder, M. Wagemaker, $J$. Electrochem. Soc., 2010, 157(5), A582-A588.

[19] J.H. Ku, J.H. Ryu, S.H. Kim, O.H. Han, S.M. Oh, $A d v$. Funct. Mater, 2012, 22(17), 3658-3664.

[20] O.B. Chae, J. Kim, I. Park, H. Jeong, J.H. Ku, J.H. Ryu, K. Kang, S.M. Oh, Chem. Mater, 2014, 26(20), 58745881.

[21] J. Jang, S.-M. Kim, Y. Kim, K.H. Park, J.H. Ku, J.H. Ryu, S.M. Oh, Isr. J. Chem., 2015, 55(5), 604-610.

[22] J. Dahn, T. Zheng, Y. Liu, J. Xue, Science, 1995, 270(5236), 590

[23] C.W. Park, S.H. Yoon, S.I. Lee, S.M. Oh, Carbon, 2000 38(7), 995-1001.

[24] H. Xiong, M. Slater, J. Phys. Chem. Lett., 2011, 2(20), 2560-2565.

[25] Y. Fang, L. Xiao, J. Qian, X. Ai, H. Yang, Y. Cao, Nano Lett., 2014, 14(6), 3539-3543.

[26] S. Hamaguchi, H. Yoshitake, Electrochemistry, 2009, 77(5), 373-378.

[27] M. Hibino, K. Abe, M. Mochizuki, M. Miyayama, J. Power Sources., 2004, 126(1), 139-143.

[28] C. Delmas, S. Brethes, J. Power Sources., 1991, 34(2), 113-118.
[29] C. Delmas, J.M. Cocciantelli, J.P. Doumerc, Solid State Ionics., 1994, 69(3-4), 257-264.

[30] Q. An, F. Lv, Q. Liu, C. Han, K. Zhao, J. Sheng, Q. Wei, M. Yan, L. Mai, Nano Lett. 2014, 14(11), 62506256.

[31] C. Niu, M. Huang, P. Wang, J. Meng, X. Liu, X. Wang, K. Zhao, Y. Yu, Y. Wu, C. Lin, L. Mai, Nano Res. 2016, 9(1), 128-138.

[32] H. Hirashima, S. Kamimura, R. Muratake, T. Yoshida, $J$. Non. Cryst. Solids., 1988, 100(1-3), 394-398.

[33] Y. Wei, J. Zhou, J. Zheng, C. Xu, Electrochim. Acta., 2015, 166, 277-284.

[34] S. Södergren, H. Siegbahn, H. Rensmo, H. Lindström, A. Hagfeldt, S.-E. Lindquist, J. Phys. Chem. B., 1997, 101(16), 3087-3090.

[35] K. Tasaki, A. Goldberg, J.-J. Lian, M. Walker, A. Timmons, S.J. Harris, J. Electrochem. Soc. 2009, 156(12), A1019-A1027.

[36] L.R. Pizzio, Mater. Lett. 2005, 59(8), 994-997.

[37] J. Wong, F. Lytle, R. Messmer, Phys. Rev. B., 1984, 30(10), 5596.

[38] Tsunehiro Tanaka, H. Yamashita, R. Tsuchitani, T. Funabiki, S. Yoshida, J. Chem. Soc. Faraday Trans., 1988, 84(9), 2987-2999.

[39] H. Jie, H. Park, K.-B. Lee, H.-J. Chang, J.-P. Ahn, J.-K. Park, Surf. Interface Anal. 2012, 44(11-12), 1449-1452

[40] Z.Y. Wu, G. Ouvrard, P. Gressier, C.R. Natoli, Phys. Rev. B., 1997, 55(16), 10382.

[41] F. Farges, G. Brown, J. Rehr, Phys. Rev. B., 1997, 56(4), 1809-1819.

[42] H. Yoshitake, T. Sugihara, T. Tatsumi, Phys. Chem. Chem. Phys., 2003, 5(4), 767-772.

[43] J.-Y. Shin, D. Samuelis, J. Maier, Adv. Funct. Mater, 2011, 21(18), 3464-3472.

[44] H. Kawai, M. Nagata, H. Kageyama, H. Tukamoto, A.R. West, Electrochim. Acta, 1999, 45(1), 315-327.

[45] S. Klosek, D. Raftery, J. Phys. Chem. B., 2001, 105(14), 2815-2819.

[46] G. Salek, B. Bellanger, I. Mjejri, M. Gaudon, A. Rougier, Inorg. Chem., 2016, 55(19), 9838-9847.

[47] B. Siemensmeyer, J. Schultze, Surf. Interface Anal., 1990, 16, 309-314.

[48] P. Verma, P. Maire, P. Novák, Electrochim. Acta, 2010, 55(22), 6332-6341.

[49] R. Dedryvère, S. Laruelle, S. Grugeon, L. Gireaud, J.-M. Tarascon, D. Gonbeau, J. Electrochem. Soc., 2005, 152(4), A689-A696.

[50] K.E. Swider-Lyons, C.T. Love, D.R. Rolison, Solid State Ionics, 2002, 152, 99-104.

[51] F.-M. Wang, J. Rick, Solid State Ionics, 2014, 268, 3134. 